\title{
FUNCTIONAL OUTCOME OF SCHATZKER TYPE 5 AND 6 TIBIAL PLATEAU FRACTURE TREATED BY PROXIMAL LOCKING PLATE
}

\author{
Chatla Srinivas ${ }^{1}$, Parupalli Satish ${ }^{2}$, G. V. S. Murthy33, B. Raju ${ }^{4}$
}

${ }_{1}^{1}$ Associate Professor, Department of Orthopaedics, Osmania Medical College/Osmania General Hospital, Hyderabad, Telangana, India. ${ }^{2}$ Assistant Professor, Department of Orthopaedics, Osmania Medical College/Osmania General Hospital, Hyderabad, Telangana, India. 3 Professor and HOD, Department of Orthopaedics, Osmania Medical College/Osmania General Hospital, Hyderabad, Telangana, India. ${ }_{4}^{4}$ Postgraduate Student, Department of Orthopaedics, Osmania Medical College/Osmania General Hospital, Hyderabad, Telangana, India.

\section{BACKGROUND}

ABSTRACT

Proximal tibial plateau fractures are complex and complicated intraarticular fractures around the knee joint. ${ }^{1}$ The incidence is rising among the younger population with an annual rate of incidence as high as $12 \%$ among all other fractures seen in our hospital casualty. There are various methods of treatment described in the literature, but even today managing these fractures is an enigma.

This study aims to examine the functional outcome of Schatzker type 5 and 6 proximal tibia fractures treated by open reduction and internal fixation by proximal tibial locking plate.

\section{MATERIALS AND METHODS}

This is a prospective cohort study of 54 cases of Schatzker type 5 and 6 proximal tibia fractures, aged between 19 years and 54 years during the period 2011-2015 in our hospital. All are treated by open reduction and internal fixation with proximal tibial locking plate and screws, except in two cases additional posteromedial buttress plating was done. Post-operatively, patient's leg was immobilised in posterior POP slab until suture removal. Later the limb is rested on knee brace for four weeks with an advice to do static quadriceps and ankle exercises. They were allowed to walk with brace without bearing weight on affected limb. The patient is followed up at regular intervals of 3, 6, 12 and 24 weeks. The functional outcome is assessed by Oxford knee scoring at the end of 24 weeks.

\section{RESULTS}

Excellent results are seen in $81 \%$ of cases.

\section{CONCLUSION}

Our study has shown that Type V and VI Proximal tibial fractures, treated by ORIF and Proximal locking plate produced good results in 32-month follow-up. Though, in long-term the knees are subjected to excess wear and tear of the damaged articular cartilage resulting in early secondary osteoarthritis.

\section{KEY WORDS}

Proximal Tibial Fracture, Locking Plate Osteosynthesis.

HOW TO CITE THIS ARTICLE: Srinivas C, Satish P, Murthy GVS, et al. Functional outcome of Schatzker type 5 and 6 tibial plateau fracture treated by proximal locking plate. J. Evolution Med. Dent. Sci. 2018;7(48):5141-5144, DOI: 10.14260/jemds/2018/1141

\section{BACKGROUND \\ The proximal tibial articular fractures can be caused by high} energy motor vehicle accidents or bumper strike injuries; however, sports injuries, trivial falls less frequently produce them, especially in elderly patients with osteopenia. ${ }^{2}$

High energy proximal tibial fractures should be evaluated meticulously for neurovascular injuries, compartment syndrome. The standard antero-posterior x-ray with $10^{\circ}$ caudal angulation, lateral $\mathrm{x}$-ray and computed tomography with sagittal reconstruction will help in assessing fracture pattern and comminution. MRI could assess any associated ligamentous and meniscal injuries. ${ }^{2}$

'Financial or Other Competing Interest': None.

Submission 18-09-2018, Peer Review 07-11-2018,

Acceptance 13-11-2018, Published 26-11-2018.

Corresponding Author:

Dr. Chatla Srinivas,

Flat 105, B-36, SKS Residency,

Durgabai Deshmukh Colony,

Hyderabad-500013, Telangana, India.

E-mail: sriortho68@gmail.com

DOI: $10.14260 /$ jemds/2018/1141

\section{(c) $($ ) $९$}

The proximal tibial fractures are classified earlier, according to the fracture pattern and dislocation by Hohl and Moore $^{3}$ into five types. Schatzker's classification ${ }^{4}$ was most widely used as he was the first to make the distinction between medial and lateral plateau fractures and also included the metaphyseo-diaphyseal dissociation in type 6 . The AO classification by Muller ${ }^{5}$ is more of a research tool. Recently, Luo CF et al, 6 developed a new concept of the proximal tibia as a three-column structure, which has been studied to understand posteromedial and posterolateral fragment morphology. This has led to development of 10segment classification of the tibial plateau, based on CT imaging of the proximal tibial plateau. ${ }^{6}$ This has changed the treatment strategy of Proximal tibial fractures with fracturespecific surgical approach.

Tscherne and Lobenhoffer ${ }^{7}$ emphasised the importance of distinguishing between the "pure" plateau fracture pattern and the fracture-dislocation pattern. These authors also introduced the term complex knee trauma to describe injuries associated with significant damage to two or more of the following compartments: the soft-tissue envelope of the knee, the ligamentous stabilisers and the bony structures of the distal femur and proximal tibia. 
Goals of treatment of proximal tibial articular fractures as described by Hall JA et $\mathrm{al}^{8}$ include restoration of articular congruity, axial alignment, joint stability and functional motion. Based on the type of fracture, there are various methods of treatment ranging from conservative, external fixation and open reduction internal fixation. Our study includes Schatzker's type 5 and 6 proximal tibial fractures treated by open reduction and internal fixation by proximal tibial lateral locking plate.

\section{MATERIALS AND METHODS}

This is a prospective cohort study of 54 cases of Schatzker type 5 and 6 proximal tibia fractures, aged between 19 years and 54 years, during the period 2011-2015 in our hospital. All are treated by open reduction and internal fixation with proximal tibial locking plate and screws, except in two cases additional postero-medial buttress plating was done. Postoperatively, patient's leg was immobilised in posterior POP slab until suture removal. Later the limb is rested on knee brace for four weeks with an advice to do static quadriceps and ankle exercises. They were allowed to walk with brace, without bearing weight on affected limb. The patient is followed up at regular intervals of 3, 6, 12 and 24 weeks. The functional outcome is assessed by Oxford knee scoring at the end of 24 weeks.

All the patients are clinically assessed, haemodynamically stabilised, splinted and later investigated. The $\mathrm{x}$-rays are taken in both AP and lateral views including knee and ankle joint. As a routine for all intraarticular fractures, CT scan is done with 3D reconstruction. In some cases of complex knee trauma, MRI was also done to assess the meniscal and ligamentous injuries. Doppler is done for cases with impending compartment syndrome and with extensive soft tissue injury.

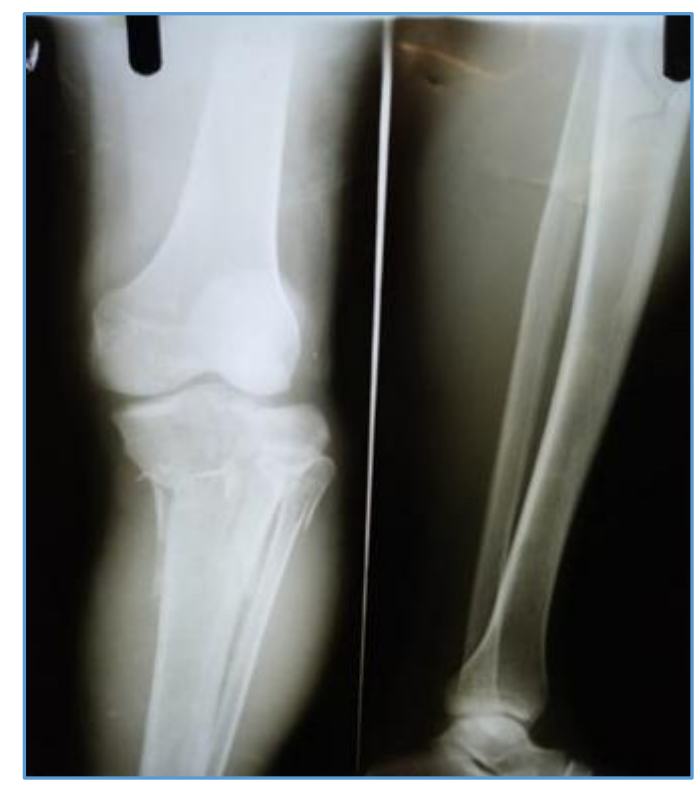

Pre-Operative X-Ray

\section{Operative Procedure}

All the patients were operated under spinal anaesthesia, with patient in supine position and under tourniquet control. Intravenous Ceftriaxone $2 \mathrm{gm}$ was given as preoperative antibiotic 15 mins before surgery. The fracture is approached anterolaterally. Under C-arm imaging, the fracture is reduced by traction and the fragments are provisionally stabilised by multiple K-wires. The depressed fracture of the articular surface is addressed by either elevating through submeniscal approach or from the contralateral bone window, followed by bone grafting or cementing. After checking the fracture reduction under $\mathrm{C}$-arm in both views, the Hockey stick locking plate is placed contouring along the lateral surface of the tibia. The upper end of the plate reaches upto the jointline and distally enough cortices are fixed for stability. In about 2 cases, a small buttress plate is fixed to address the large posteromedial fragment with a separate incision. The limb is immobilised in posterior POP slab for 10 days. While in slab, patient is advised static quadriceps exercise and Ankle and Foot exercise. After suture removal, limb is rested in long knee brace for 4 weeks. They were advised for knee ROM and static quadriceps strengthening exercises. They were allowed to walk with toe-touch weight bearing on axillary crutches. Patient is asked to come for regular follow-up at 3, 6, 12 and 24 weeks. Each time patient was examined for wound healing, pain scoring, knee movement and radiological assessment. After 6 months, all the 54 cases were assessed by Oxford knee score.

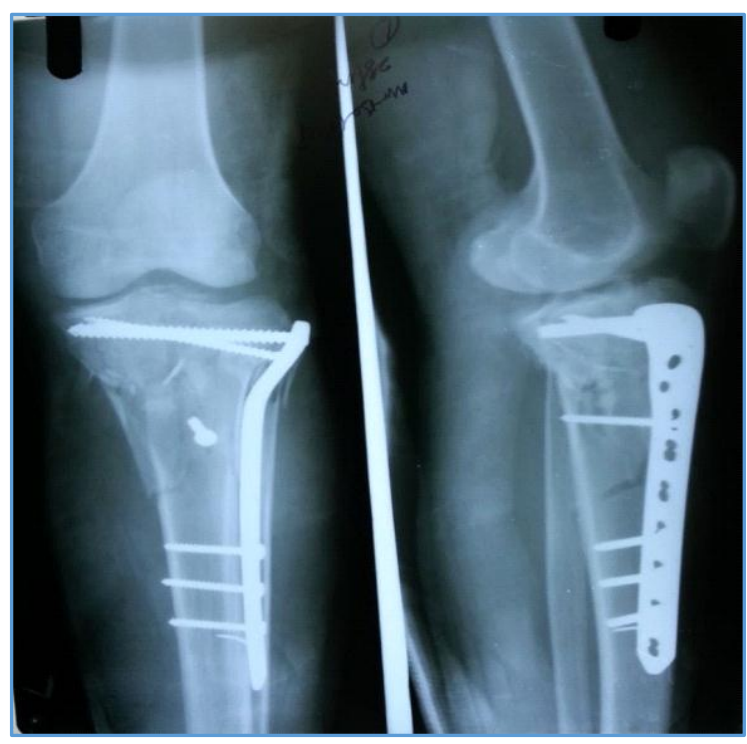

Post-Operative X-Ray

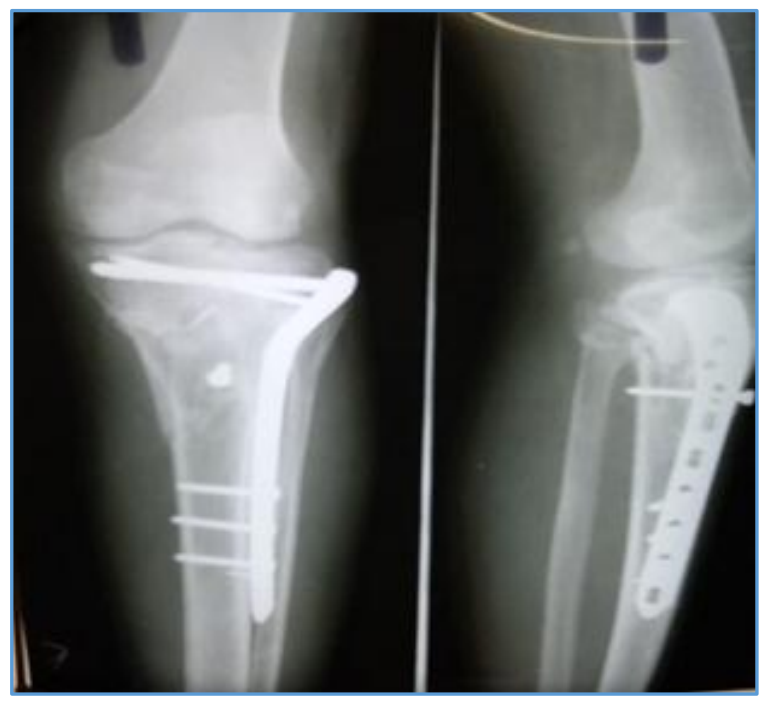

Follow-Up X-Ray 


\section{RESULTS}

We have selected 54 cases of Schatzker's type 5 and 6 Proximal tibial fractures visited during 2011-2015 in our hospital. Six patients were females and remaining 48 were males. The patients are aged between 19 years and 54 years with mean age of 34 years. The common cause of fracture was road traffic accident. 12 cases were open fractures, of which 10 were grade 1 and rest of the two cases were grade 2 , as per Gustilo-Anderson classification.

Among the 54 cases, 42 patients were treated immediately within 24 hours. Of the remaining 12 patients, surgery was delayed by an average 7 days. 8 cases have developed compartment syndrome with skin blisters which were promptly treated with fasciotomy. Four cases were delayed due to medical management of the co-morbid conditions. We have observed that in 10 cases there were associated injuries like lateral popliteal nerve injury in 2 cases, tibial tubercle avulsion in 2 cases, meniscal injuries and ligament injuries in 6 cases. The nerve injury has recovered in 10 weeks and the meniscal injuries were treated conservatively.

Almost all the cases had fracture union in about 20-28 weeks, except in four cases the union was delayed due to infection. 6 cases had delayed wound healing due to persistent tissue oedema and superficial wound infection. 4 of the open fracture cases developed deep infection of the fracture. They were all treated by serial debridement and intravenous antibiotics. Three cases have recovered, but one patient needed implant removal and Ilizarov external ring fixation.

All the 54 cases were evaluated for functional outcome by Oxford knee score. 25 cases have a score ranging from 40-48, 20 cases scored 30-39 and the rest of 9 cases scored 20-29.

\begin{tabular}{|c|c|}
\hline Oxford Knee Score & No. of Patients \\
\hline $0-19$ & 1 \\
\hline $20-29$ & 3 \\
\hline $30-39$ & 7 \\
\hline $40-48$ & 54 \\
\hline Total & $\mathbf{6 5}$ \\
\hline \multicolumn{2}{|c|}{$\begin{array}{c}\text { Table 2. Functional Outcome in Terms of Oxford Knee } \\
\text { Score }\end{array}$} \\
\hline
\end{tabular}

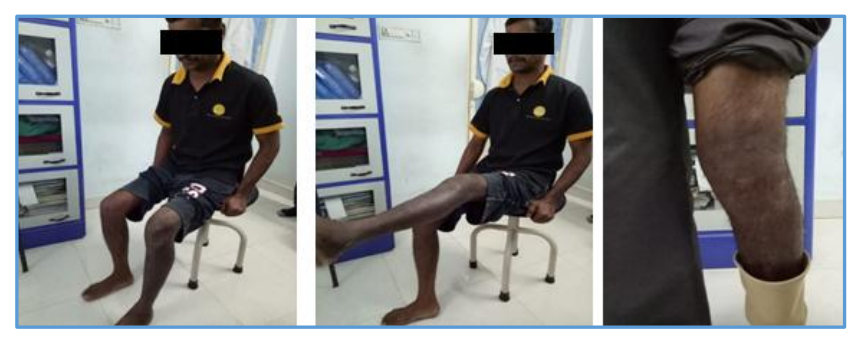

\section{DISCUSSION}

The Schatzker's proximal tibial fractures type 5 and 6 are very complicated and critical intraarticular fractures. They mostly resulted due to high energy injuries, hence further damaging the surrounding soft tissue and complicating the fracture healing. There are various methods described in the literature ranging from conservative to operative procedures. Some of the older methods and implants have become obsolete now. For the last decade, the morphology of the fractures and its associated soft tissue injuries have been studied closely. With the advent of new techniques, instrumentation, newer designs of implants, the management of these highly critical fractures has resulted in better procedures. But still, the final functional outcome needs to be further improvised.

Moore, Patzakis and Harvey ${ }^{10}$ reported a $23 \%$ incidence of infection in bicondylar tibial plateau fractures treated with internal fixation. Wound dehiscence or infection occurred in eight of 11 fractures stabilised with medial and lateral plates. An extensive "Mercedes" incision was used in many. Young and Barrack ${ }^{11}$ reported similar results: seven of eight fractures treated with double plating were complicated by infection.

Attempts have been made to reduce the incidence of complications in these fractures by using less extensile exposures and indirect reduction techniques and by supplementing lateral buttress plate fixation with a medial two-pin external fixator or small antiglide plate rather than a second bulky medial buttress plate. Mills and Nork ${ }^{12}$ suggested that dual plating could be achieved with minimal soft-tissue dissection by using a more anterior skin incision and limiting subperiosteal dissection to fracture margins and to the area of anticipated plate application. Ballmer, Hertel and Nötzli ${ }^{13}$ reported the use of small fragment $(3.5-\mathrm{mm}$ screws) AO/ASIF T-plates for fixation of tibial plateau fractures (type B, four type C). At 42-month follow-up, most of the fractures had excellent or good results. Anatomical or nearly anatomical reductions were obtained in $86.7 \%$. There were no infections or soft-tissue complications. Ballmer et al suggested that the smaller diameter and increased malleability of the small fragment T-plate provided better buttressing of the osteochondral fragments than the larger pre-contoured AO/ASIF T-plates and L-plates $(6.5-\mathrm{mm}$ screws).

Benirschke et al reported no non-unions or deep infections in grade II and grade III open complex (Schatzker types V and VI) tibial plateau fractures treated by experienced surgeons with a standard protocol of thorough debridement, immediate rigid internal fixation and delayed closure at 5 days. Supplemental medial external fixation was used in five patients and five patients were treated with Zplates. Tscherne and Lobenhoffer ${ }^{7}$ recommended temporarily spanning the knee with an external fixator in patients with severe soft-tissue injury. Internal fixation can be done after swelling has decreased.

External fixation using either half-pin fixators or ring and wire fixators also has been advocated as definitive fixation for complex tibial plateau fractures. Cannulated screws can be used as accessory fixation of the articular surface. An external fixator placed below the knee can maintain articular reduction and axial alignment and allow early motion. Minimal soft-tissue dissection is required for application of an external fixator, which theoretically should reduce wound complications.

Hall JA, Beuerlein MJ, McKee MD; Canadian Orthopaedic Trauma Society, ${ }^{8}$ performed a multicentre, prospective, randomised clinical trial in which standard open reduction and internal fixation with medial and lateral plates was compared with percutaneous and/ or limited open fixation and application of a circular fixator for displaced bicondylar tibial plateau fractures (Schatzker types V and VI). No significant differences between the groups in terms of demographic variables, mechanism of injury or fracture 
severity and/ or displacement. However, patients in the circular fixator group had less intraoperative blood loss than those in the open reduction and internal fixation group, and spent less time in the hospital (9.9 days and 23.4 days, respectively; $p=0.024$ ). The quality of osseous reduction was similar in the groups. These outcomes were not significantly different at two years' follow-up for knee ROM, pain, stiffness.

Open reduction and internal fixation with plating is considered one of the acceptable methods of treatment in Schatzker type V and type VI tibial plateau fractures. Excellent results in $81 \%$ of the cases have been reported in one of the series by Lachiewicz and Funcik. ${ }^{14}$ Oh et al $^{15}$ have also reported excellent results in $91 \%$ of the cases treated with open reduction and internal fixation of proximal tibial plateau fractures. Touliatos et al ${ }^{16}$ have reported excellent result in $57 \%$ of their cases, while in our series $81 \%$ had excellent and $10.7 \%$ had good functional outcome.

Kumar, Gaurav Sharma and Kamran Farooque, they have studied 65 patients of proximal tibial fractures treated by ORIF with a mean follow-up of 32 months and concluded that open reduction and internal fixation is an excellent method of treatment of type $\mathrm{V}$ and type VI tibial plateau fractures in judiciously selected cases. The high Oxford knee score in these cases supports the fact that operative intervention can alter the lifestyle of the patients markedly.

\section{CONCLUSION}

Type V and VI Proximal tibial fractures, treated by ORIF and Proximal Locking plate had good results in 32-month followup. Though, in the long-term, the knees are subjected to excess wear and tear of the damaged articular cartilage resulting in early secondary osteoarthritis.

\section{REFERENCES}

[1] Canale ST, Beaty JH. Campbell's operative orthopaedics. 11 $1^{\text {th }}$ edn. 2008.

[2] Egol KA, Koval KJ. Rockwood \& Green's fractures in adults. In: Bucholz RW, Heckman JD, Court-Brown CM, eds. Fractures in adults. $6^{\text {th }}$ edn. Philadelphia: Lippincott Williams \& Wilkins c2006.

[3] Hohl M. Fractures of the proximal tibia and fibula. In: Rockwood C, Green D, Buckolz R, eds. Fractures in Adults. 3rd edn. Philadelphia: JB Lippincott 1991: p. 1725-61.

[4] Schatzker J, McBroom R, Bruce D. The tibial plateau fracture. The Toronto experience 1968-1975. Clin Orthop Relat Res 1979;138:94-104.
[5] Müller ME, Nazarian $S$, Koch $P$, et al. The comprehensive classification of fractures of long bones. Berlin: Springer 1990.

[6] Luo CF, Sun H, Zhang B, et al. Three-column fixation for complex tibial plateau fractures. J Orthop Trauma 2010;24(11):683-92.

[7] Tscherne H, Lobenhoffer P. Tibial plateau fractures. Management and expected results. Clin Orthop Relat Res 1993;(292):87-100.

[8] Hall JA, Beuerlein MJ, McKee MD, et al. Open reduction and internal fixation compared with circular fixator application for bicondylar tibial plateau fractures. Surgical technique. J Bone Joint Surg Am 2009;91:7488.

[9] Gustilo RB, Merkow RL, Templeman D. The management of open fractures. J Bone Joint Surg Am 1990;72(2):299-304.

[10] Moore TM, Patzakis MJ, Harvey JP. Tibial plateau fractures: definition, demographics, treatment rationale and long term results of closed traction management or operative reduction. J Orthop Trauma 1987;1(2):97-119.

[11] Young MJ, Barrack RL. Complications of internal fixation of tibial plateau fractures. Orthopaedic Review 1994;23(2):149-54.

[12] Barei DP, Nork SE, Mills WJ, et al. Functional outcomes of severe bicondylar tibial plateau fractures treated with dual incisions and medial and lateral plates. J Bone Joint Surg Am 2006;88(8):1713-21.

[13] Ballmer FT, Hertel R, Nötzli HP. Treatment of tibial plateau fractures with small fragment internal fixation: a preliminary report. J Orthop Trauma 2000;14(7):467-74.

[14] Lachiewicz PF, Funcik T. Factors influencing the results of open reduction and internal fixation of tibial plateau fractures. Clinical Orthopaedics and Related Research 1990;(259):210-5.

[15] Oh CW, Oh JK, Kyung HS, et al. Double plating of unstable proximal tibial fractures using minimally invasive percutaneous osteosynthesis technique. Acta Orthopaedica 2006;77(3):524-30.

[16] Touliatos AS, Xenakis T, Soucacos PK, et al. Surgical management of tibial plateau fractures. Acta Orthopaedica Scandinavica Supplement 1997;68(275):92-6. 